Title: Cock-Ups and Slap-Downs: A Quantitative Analysis of Conspiracy Rhetoric in the British Parliament 1916-2015

Authors: Andrew McKenzie-McHarg and Rolf Fredheim

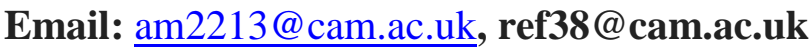

Affiliation: Centre for Research in the Arts, Social Sciences and Humanities (CRASSH), University of Cambridge. Alison Richard Building, 7 West Road, Cambridge, CB3 9DT 
Abstract: In view of the negative connotations associated with conspiracy theories, what have been the effects of the term's entry into popular vocabulary in the second half of the twentieth century? Has the ascendancy of the term "conspiracy theory" been correlated with a reluctance to allege conspiracy? In this paper we use Hansard, the record of British parliamentary debates, as a source of empirical data in demonstrating a significant and steady reduction in the number of conspiracy claims advanced in parliament; a pattern consistent with the broader marginalization of conspiracy rhetoric. This trend was reinforced by a trope that established itself in the 1980s and juxtaposed "conspiracies" with "cock-ups." The British expression "cock-up" denotes a blunder or act of incompetence. In the second part of this paper, we argue that the preference for "cock-up theories" over "conspiracy theories" reflects how a policy geared towards privatisation and deregulation tended to characterize government action in terms of incompetence, and not of malfeasance.

Keywords: conspiracy, conspiracy theory, Hansard, Parliament, content analysis, computational methods, liberalism, neoliberalism 


\section{Cock-Ups and Slap-Downs: A Quantitative Analysis of Conspiracy Rhetoric in the British Parliament 1916-2015 ${ }^{1}$}

\section{Introduction}

At approximately 7:55 pm on 23 November 1965 Lord Chalfont made the following statement to the British House of Lords: "My Lords, one or two noble Lords opposite seem, from things which have been said this afternoon, to be addicted to the conspiracy theory of government and history." (Hansard, 23 Nov 1965, col 883). The context was a debate about the reorganization of the reserve army. For current purposes Lord Chalfont's remark is, however, noteworthy for another reason: it was the first time that the phrase "conspiracy theory" was deployed in a debate within the British Parliament.

It might be noted that Lord Chalfont actually spoke of the "conspiracy theory of government and history." Locutions linking "conspiracy theory" to abstract nouns in this manner were frequent during the Cold War period and echo Karl Popper's critique of the “conspiracy theory of society," which he had originally formulated in 1948 (Popper 2002). Although Popper's coinage did not represent the first use of the specific term "conspiracy theory," his arguments helped to bring about a situation in which both the naming and defaming of the phenomenon were intimately linked. Thus, it is of no surprise that on the occasion of its first mention in the British Parliament the term was already laden with negative connotations, audible in Lord Chalfont's insinuation that some of his fellow lords were "addicted" to the "conspiracy theory of government and history." As a result of its pejorative edge, the term "conspiracy theory" lent itself to deployment in what we have called - in a consciously colloquial fashion - a slap-down. Slap-downs are rhetorical moves that rebut an opponent's claims by discounting their seriousness. In other words, they do not engage with a truth-claim on its own terms but instead dismiss the claim on the grounds that 
the very premises underpinning it are problematic and untenable. They can furthermore take on an ad hominem quality by ridiculing the opponent as a "conspiracy theorist."

And yet as ridiculous as some claims made by conspiracy theorists might be, no one can deny the fact that conspiracies do occur from time to time in the real world. This paper will not stake its claim to originality on an argument drawing attention to the problem this implies, namely: that the terms "conspiracy theory" and "conspiracy theorist" can be deployed to stifle inquiry into situations in which a genuine conspiracy is lurking or which at least warrant such suspicions (Husting and Orr 2007); some philosophers have been particularly insistent in pointing this out (Pigden 1995; Coady 2012; Dentith 2014). The current paper aims rather to shed new light on this phenomenon by quantitatively measuring the correlation between the level of conspiracy claims and the presence of "conspiracy theory" as a term indicating an a priori skepticism of such claims.

Any attempt to measure the changing level of conspiracy accusation since the advent of the term "conspiracy theory" requires a body of textual material marked by such a degree of institutional continuity as to allow comparisons between statements made in one period with those made in another. The source from which we extracted Lord Chalfont's remark is Hansard; thus the name given since the early nineteenth century to the transcripts of the UK parliamentary debates. Hansard provides a useful body of discourse for testing the changing relationship between accusations of conspiracy and slap-downs that appeal to the term “conspiracy theory." Given that Chalfont made his remark in 1965 we decided for simple reasons of symmetry to compare the fifty years of debates prior to this auspicious yet inconspicuous event (1916-1965) with the fifty years after (1966-2015).

Our inquiry was guided by the following set of questions: What effect does the absorption of "conspiracy theory" into the vocabulary of parliamentary debate have on the level of conspiracy accusations? How does the appeal to the notion of "conspiracy" change as 
parliamentarians begin to anticipate a "slap-down" delivered by an opponent in the form of some usage of "conspiracy theory"? Is an increased chance of a slap-down correlated to a measurable decline in the willingness to voice the accusation in the first place, or at least to a shift in the vocabulary employed in formulating it?

Very roughly expressed, our working hypothesis presumed an inverse relationship: more "conspiracy theory" was expected to correspond to less "conspiracy." Yet complexities lie in wait here; not every mention of "conspiracy" (without "theory") represents an accusation of conspiracy that might conceivably expose a speaker to a slap-down invoking "conspiracy theory". On the other hand, the term "conspiracy theory" need not only find use in slap-downs. To appreciate this possibility, it is only necessary to consider what we have called preemption, paradigmatically expressed in disclaimers such as: "I am not a conspiracy theorist, but ...," or "I generally don't believe in conspiracy theories, but ..." Such statements often follow the "but" with what might plausibly be described as a conspiracy theory.

Our attempt in this paper to get a better analytical grip on the stigmatizing effect of interest proceeds from a review of the literature and moves on to a description of our methodology. This is followed by a discussion of our findings. In the last part of the paper we turn our attention to a subsidiary phenomenon. Upon immersing ourselves in the material culled from Hansard, we began to notice a tendency to pit "conspiracy" against "cock-up," starting around the 1980s. In the final section we develop an argument to explain this trend.

\section{The state of research: Approaching a more objective measure of conspiracy theorizing}

For a number of years the research into conspiracy theories has been developing momentum. One simplistic explanation for this might be that conspiracy theories themselves are on the rise (see e.g. Barkun 2013). However, growing academic interest in the phenomenon need not correlate with an increased prevalence of conspiracy theorizing; it is not always the case that researchers re-direct their resources to the study of a particular 
something whenever there is more of that something. Some scholars (esp. Thalmann 2014) have pushed back against the alarmism by arguing that western liberal societies have over the last fifty years or so successfully marginalized conspiracy theories. Even if in times of Trump and Brexit such views need to be revisited, the argument at the very least indicates that we are approaching a more objective assessment of the phenomenon in question: the object of study is no longer being confused with the study of the object.

Two recent works on conspiracy theories in the American context provide insights that are germane to such considerations. Drawing on letters from readers published by the New York Times and the Chicago Tribune, the political scientists Joseph Uscinski and Joseph Parent have identified the 1890s and the 1950s as the two periods in which the level of conspiracy theorizing in American public discourse peaked. Yet in passing they also note that since the 1960s the presence of conspiracy theories has decreased: "From 1964 on, conspiracy theories average half a percent of the letters per year, while before 1964 conspiracy theories are more than double. The data suggest one telling fact: we do not live in an age of conspiracy theories and have not for some time" (Uscinski and Parent 2014, 110111). Admittedly, Uscinski and Parent were impressed first and foremost by the way their data indicated a relatively stable level of conspiracy theorizing in American public discourse. Their efforts focused on explaining this stability in terms of the cognitive constants created by a two-party political system. Indeed, they characterized the pattern of conspiracy theorizing in the United States as "hydraulic; conspiracy theories are a liquid that, when displaced, soon find their level again" (Uscinski and Parent 2014, 109). Such an interpretation, which implies a constant level of conspiracy theorizing, fails to account for their secondary finding of a decline in conspiracy theories since the 1960s. Attempting to reformulate their interpretation with a view to the phenomenon of interest for this paper, we could ask: why has the closed hydraulic system of American politics been slowly leaking 
some of its conspiracy-theorizing fluid since the 1960s? Where is the leak and what has caused it?

Seeking an answer to such questions, we turn to Michael Butter's recent work Plots, Designs and Schemes (2014), which also argues that conspiracy theories have been in decline of late. The broader historical sweep of Butter's inquiry allows him to put into perspective anxieties about current levels of conspiracy theories; a glance back at the nineteenth century reveals that conspiracy theories were almost all-pervasive in American political culture during this period. According to Butter, the retreat of conspiracy theories from the midtwentieth century onwards corresponds to their social and intellectual marginalization. Butter's substantive investigation ends with the Red Scare of the 1950s but in concluding he remarks that the alleged subsequent retreat of conspiracy theories resembles that of issues such as racism, homophobia, sexism and xenophobia (Butter 2014, 290). A casual survey of popular media outlets indicates that society today is extremely sensitive about, for example, racism; public remarks that are deemed racist attract immediate and vociferous censure. This heightened sensitivity to racism does not, however, reflect a more racist society. In a parallel manner, a society in which there is more talk of conspiracy theories does not equate to a society more enthralled to conspiracy theories but rather to one that is more sensitive to them.

Butter's study thus converges with that of Uscinski and Parent in diagnosing an attenuation of conspiracy theorizing in American public discourse. And yet neither study fully engages with this trend. Consequently, we have taken their arguments as our cue to pursue the matter further. Another recent study from the French sociologist Luc Boltanski has affirmed the relevance of our inquiry. As Boltanksi writes: "It is hard to know whether the belief in conspiracies on the part of large numbers of people has actually grown in considerable proportions in recent decades, as many scholars have claimed. Longitudinal studies would be required to shore up this position, but these have not been initiated as yet, 
and it is hard to see how they could be carried out, especially as regards the past." (Boltanski 2014, 197). It is our contention that analyzing Hansard in terms of shifts in its semantics and contents has the potential to yield the kind of longitudinal study that Boltanski identifies as a desideratum in the current state of research into conspiracy theories.

Our point of departure was the observation of a curious coincidence: the 1960s was both the period in which the term "conspiracy theory" started to make inroads into popular discourse (particularly in the wake of the JFK-assassination) and the period in which conspiracy theorizing started its decline. By examining these phenomena using Hansard, we also seek to broaden the focus of the discussion by looking beyond American political culture. Just as the proliferation of studies on conspiracy theories need not necessarily reflect a corresponding proliferation of conspiracy theories themselves, it would be rash to surmise from the predominant focus of research on American political culture that conspiracy theories are a specifically American phenomenon. ${ }^{2}$ Admittedly we remain within the orbit of western liberal democracies, well aware that broader international comparative work still needs to be done. Studies in the context of other political cultures cannot take a decline in conspiracy theorizing for granted, and it might even be the case that the decline observed by the aforementioned studies represents only a short interlude in the longer history of conspiracy theories.

A further characterization of our research is warranted at this point. In what follows we aim to maintain a 'middle altitude' in attempting to survey the level of conspiracy theorizing as revealed by debates in the British parliament. This approach is necessary because, as will soon become apparent, the pattern of interest, namely: the relationship between conspiracy claims and slap-downs invoking the term "conspiracy theory," is not discernible from the rarefied heights of a purely statistical analysis of word usage. Once it became apparent that such an analysis relying solely on quantitative measures of the terms of 
interest would be inadequate to the task at hand, we resolved to engage in content analysis. Content analysis differs, however, not just from the high-altitude approach of statistical analysis but also from the low-altitude approach of contextual analysis. A consideration of context would undoubtedly be necessary in addressing other issues highly relevant to the phenomenon in question. These issues include, for example, the more specific motives and propensities at work when claims of conspiracy are voiced or rebutted. In retaining our focus on the specific question about levels of conspiracy theorizing, we postpone for a later day the more fine-grained research that would examine other such aspects of conspiracy theorizing and its social and political acceptability.

\section{Methodology: Content analysis and categories of usage}

In the interest of maintaining "the cut and thrust of debate," parliamentary practice in the House of Commons does not allow written speeches (Jack 2011, 430). Similar provisions exist for the House of Lords, even if question time and debate are less conflictual and characterized by a greater degree of decorum (Russell 2013). Whatever difference in specific procedure and more general culture exist between the two chambers, there are good reasons to regard Hansard as a source providing a less filtered view of general linguistic usage than the letters to the editors analyzed by Uscinski and Parent or the literary texts analyzed by Butter (although questions undoubtedly remain about the degree to which this body of material can be seen as representative of linguistic usage elsewhere in society).

This source has furthermore become accessible for the application of computational methods since Millbank System, an outfit which describes itself as "a small, informal group working within the UK Parliamentary Service," have digitized Hansard and made it accessible in an online format at http://hansard.millbanksystems.com. At the time of writing digitization extends to March 2005. We have therefore supplemented the collection with the records of the more recent parliamentary debates available at http://www.parliament.uk. (See 
Bright 2012 for another example of research employing the digitized Hansard as a data source).

We used a computer script to collect and archive the contents of Hansard. Subsequent enquiry was restricted to oral statements in the Lords or the Commons. We ordered the data on the basis of decades (1916-1925, 1926-1935, etc., 2006-2015) and began to consider the incidence of $\mathrm{C}$ within each decade, where $\mathrm{C}$ is shorthand for any usage of "conspiracy" or one of its lexemes (conspire / conspiracies / conspirators / conspiratorial / etc.). ${ }^{3}$ In our dataset C appears 12,014 times across 6,477 separate statements (a statement being a speech or intervention from an MP). This in turn correspond to a presence of $\mathrm{C}$ in 3,936 debates.

An examination of the distribution of $\mathrm{C}$ over time relative to all other words reveals that the heyday of conspiracy rhetoric in the British parliament occurred in the two decades 1916-1935, a period coinciding first with WW1 and then with an intensification with the struggle for independence in Ireland, India and in other colonies of the British Empire. Obviously a thematic coding of the material could be expected to yield interesting insights into the shifting locus of conspiracy suspicions. The focus of the present study falls, however, on the specific relationship between the emergence of the term "conspiracy theory" and broader patterns of conspiracy rhetoric. To this end we identified statements mentioning CT, that is: "conspiracy theory" or one of its lexemes (conspiracy theories / conspiracy theorist(s)). As indicated in this article's opening paragraph, this subset of C exists from 1965 onward in the historical record provided by Hansard. The data set contains approximately 680 occurrences, corresponding to 528 statements made in 433 debates. This represents $6.2 \%$ of all statements across the entire data set of C, and 8.2\% within the data set from 1965 onwards.

In accordance with its chief usage as a "slap-down," "conspiracy theory" frequently describes and disparages the explanations others might posit for events. An exception 
occurred in 2003 when the MP Parmjit Dhanda asserted that "we have a theory, Mr Speaker; you might say it is something of a conspiracy theory" (Hansard, 26 Nov 2003, col 13).

Dhanda's remark represents a rare case of someone designating their own explanation as a "conspiracy theory," although even in this case the "something of a ..." betrays a qualified embrace of conspiracy theory as the mode of explanation.

In order to identify whether parliamentarians were alleging conspiracies or rather rebuking others as conspiracy theorists we conducted a content analysis. We designed a browser-based application that interacted with the database of statements. Statements were grouped by decade. A generator selected a decade at random, from which it then selected a random statement not yet graded by the coder. Following a trial-run, the grading was conducted independently by the authors. In total, $20 \%$ of the statements were graded, and $15 \%$ of the graded statements were graded by both coders. The coding achieved a high measure of intercoder reliability for each category, with the exception of statements classified as "hedging" (see below). All statements assigned to the "hedging" category were removed from the quantitative analysis. This processes yielded a percentage agreement of 92.3, and Krippendorff's Alpha of 0.796.

The categories used were:

1. Legal / Technical Usage: Given that conspiracy is a common-law crime and in view of the fact that parliamentary legislation and judicial rulings intersect in manifold ways, it is unsurprising that much usage of $\mathrm{C}$ falls within this category. Legal and technical usage of $\mathrm{C}$ is largely irrelevant for our inquiry as such usage does not for the most part provoke ripostes appealing to $\mathrm{CT}$; to claim that those charged with arson conspired to commit the crime does not invite the rebuke that such an allegation is tantamount to a conspiracy theory. Likewise, when an MP speaks of a bill comprising of "elements concerned with both criminal evidence and conspiracy" 
(Hansard, 2 Sept 1998, col 840), then it is hard to envisage how another MP might feel compelled to invoke CT in response or, more generally, to administer a slapdown targeting such a usage of $\mathrm{C}$.

2. Metaphorical Usage: There is metaphorical usage of $\mathrm{C}$ such as in the common phrase: "circumstances have conspired to ...", which is similarly unlikely to generate a response appealing to CT. This is, however, not to say that the rise of CT has not caused shifts in metaphorical usage. In fact, a preliminary test we conducted on a purely numerical basis compared usage of "conspiracy theory" to usage of “conspiracy of silence," an expression indicating an unspoken agreement to keep hush about some event, habit or relationship. The comparison suggested itself as both usages were roughly commensurate in scale (which was not the case with $\mathrm{C}$ alone, whose usage was much larger). In Hansard, usage of "conspiracy theory" begins to outpace usage of "conspiracy of silence" by the early 1970s. ${ }^{4}$ Our (tentative) explanation for this was the same as for the more general effect we hoped to observe: the negative connotations associated with "conspiracy theory" began to discourage usage of an expression such as "conspiracy of silence," even if in the case of this expression the appeal to "conspiracy" had a more metaphorical character.

3. Conspiracy Claims: These are simple accusations or allegations of conspiracy. As an example we point to the statement made by the Chancellor of the Exchequer Philip Snowden who on 13 March 1930 in a sitting of the House of Commons asserted "that there has been this deliberate conspiracy on the part of certain interests to discredit the Government" (Hansard, 13 Mar 1930, col 1550). Or on the 7 April 1948 one could have heard in the same chamber the following statement: "it is perfectly correct to say that there was a conspiracy in the Press" (Hansard, 7 Apr 1948, col 193). Such unabashed usage of $\mathrm{C}$ is often accompanied by alarmism but we are obviously in no 
position to judge the merit of each claim or otherwise. The question of interest is whether the enthusiasm in making such claims has been dampened by the anticipation that they might expose the speaker to ridicule often framed in terms of CT.

4. Straight-Faced Rejection: it is possible to reject a $\mathrm{C}$ claim on the grounds that it is not true; or at least not true in the way a previous speaker has alleged. Thus in response to allegations that the European Constitution was part of a "conspiracy" or "plot to create a European superstate" the Labour MP James Plaskitt made the following declaration to the House in 2004: "The truth of the matter is that there is no plot here. There is nothing sinister going on at all. There is no stealthy move to impose some European superstate" (Hansard, 9 Sept 2004, col 927). His statement rebuts the truth of the allegation without suggesting any absurdity associated with the notion of a plot or conspiracy in this context.

5. Slap-Downs: A slap-down represents a different rhetorical strategy than a straightfaced rejection; it desists from taking the accusation seriously on its own terms and instead dismisses it on the a priori grounds of its inherent ridiculousness. The important point for our inquiry was that, while this strategy often invokes CT, it need not necessarily do so. Thus, in 1948, at a time when CT was yet to enter the vocabulary of the British Parliament, we find the following remark made by Lord Brand in the House of Lords: "Dr. Dalton has stated that he feels there is a conspiracy against him in the financial Press and in the City. I have lived and worked for 40 years or so in the City, and I cannot think of any better word to use than to say that any idea of a conspiracy in the City is moonshine. Everybody living in the City knows that." (Hansard, 21 Apr 1948, col 267). The Viscount Swinton echoed this sentiment some time later in the same debate by speaking of "Dr. Dalton's nonsensical talk about conspiracy." (Hansard, 21 Apr 1948, col 315). Such statements dismiss the claims of 
Dr. Dalton not because they are factually false but because they are deemed inherently ridiculous.

6. Hedging: This intermediate group of statements proved slippery and was subsequently removed from the quantitative analysis. This category contains statements that fall into the cracks of the typology outlined above because they backed away from a full-voiced claim of conspiracy or rejection of such claim. Thus, the statement: "I believe that there is something like a conspiracy to prevent full and free discussion of this bill” (Hansard, 3 May 1948, col 992), counts as an exemplary form of hedging. Other forms include counterfactuals, hypothetical statements, and rhetorical questions. In practice, the hedging category proved a residual category, containing many statements that the coders deemed uncodable.

\section{Results and Discussion: fewer C claims, more CT slap-downs}

The following example can serve as paradigmatic in demonstrating the dynamic between conspiracy claims and slap-downs. In a debate on 29 April 1980 the conservative MP for Northampton, Antony Marlow, asked the Secretary of State for Social Services Patrick Jenkin about the belief that there was a "long-term conspiracy to prevent the people of this country knowing the size of the immigrant population" (Hansard, 29 Apr 1980, col 1306). Marlow seemed to share this belief; he certainly does not distance himself from it. Jenkin responded: "My hon. Friend would not expect me to endorse the conspiracy theory" (Hansard, 29 Apr 1980, col 1306). This case demonstrates how an allegation of "conspiracy" can trigger a slap-down appealing to the term "conspiracy theory". Jenkin did not bother to provide a careful and detailed refutation of Marlow's allegation. Instead, true to its function as a slap down, he believed it was sufficient to dismiss the allegation as a conspiracy theory.

The 1980s represent an interesting period for our study as other examples similar to the one just cited illustrate the clash of two semantic traditions: on the one hand, a naive 
tradition of invoking "conspiracy" as shorthand for mischief and misdemeanors in high places, and a more recent and more knowing tradition of confronting such unabashed appeals to "conspiracy" with the denigration achieved by applying the term "conspiracy theory" to them. 1982 offers four such cases and 1984 a further two of someone decrying "conspiracy," only to find this rebutted and, indeed, slapped-down by a riposte invoking "conspiracy theory." Reading such exchanges gives a glimpse of the process that inculcated in parliamentarians a greater caution in invoking the charge of "conspiracy."

Given that rejections and slap-downs respond to conspiracy claims, the incidence of C in the context of a rejection or slap-down does not carry the same weight as its incidence in a claim, because the rejection or slap-down is likely to adopt some of the language (including C) employed in the conspiracy claim (although it is important to emphasize that a slap-down using $\mathrm{C}$ or $\mathrm{CT}$ is not necessarily responding to a claim in which $\mathrm{C}$ appears; the claim might have used an alternative vocabulary (e.g. plot, collusion, etc.) or might have only insinuated conspiracy without using the word). This gives rise to complexities, which, because they apply to all periods within our data sample, we can elide as we are primarily interested in a relative comparison of the periods to each other. Our methodology simply asks: is there a shift in the relative incidence of $\mathrm{C}$, in particular as it pertains to conspiracy claims and slapdowns. ${ }^{5}$

We illustrate our results as a bar graph for the relative percentages of conspiracy claims and slap-downs, with a further breakdown in the latter category for those slap-downs employing CT (figure 1). A table containing the percentage of incidence by coding category for all C statements within each decade may be seen in Appendix 1.

[FIGURE 1 HERE]

Figure 1 demonstrates that, since CT entered parliamentary vocabulary, slap-downs constitute an ever larger proportion of all mentions of C. Although fluctuating, over the 
period 1916-65 slap-downs constituted between $4 \%$ and $11 \%$ of usage per decade; from the first mention of CT until the decade 1985-1995, slap-downs rose to represent around a quarter of all usage of $\mathrm{C}$. This is paralleled by a steady rise in the use of $\mathrm{CT}$ as the operative term for the slap-downs. In 2006-2015 two-in-three slap-downs mentioned CT. Indeed, in the decade 1995-2004, there was an even higher percentage of slap-downs using C and CT than claims using $\mathrm{C}$ (which serves as a reminder that not every slap-down involving $\mathrm{C}$ or $\mathrm{CT}$ necessarily responds to a claim involving C).

It is important to note that, because we are dealing with percentages, every percentage increase in one category will correspond to a percentage decrease for the remaining categories. To account for the distortion this causes, we combined two data sources: on the one hand, the total distribution of conspiracy mentions, and on the other, the graded sample which reveals the likelihood that a given statement represents a conspiracy claim or a slapdown. The graded statements are grouped by decade; we used the points of a LOESS curve (Local Polynomial Regression) to arrive at annualised point estimates of the proportion of C statements that were slap-downs and the proportion that were conspiracy claims. Multiplying the estimated proportion by the observed number of conspiracy mentions yields an estimate of the number of C claims and slap-downs per year. To illustrate, in 1916-1925 "conspiracy" was mentioned in $0.68 \%$ of statements in Parliament. According to our results, $52 \%$ of these statements were conspiracy claims. Multiplying $0.68 \%$ by 0.52 gives an estimate that $0.36 \%$ of all statements in 1916-1925 were conspiracy claims. For latter decades, this proportion steadily decreases. This changing dynamic can be seen by contrasting Figures 1 and 2: in Figure 1 an ever smaller proportion of statements mentioning conspiracy were conspiracy claims; Figure 2 shows that the proportion of statements in parliament which mention conspiracy was relatively stable.

[FIGURE 2 HERE] 
Future multivariate analyses will consider time series approaches to modeling these data; here we include a simple linear regression model to broadly determine whether each group of statements is becoming more or less common, and whether the results generalized by the data grouped by decades holds also for the annual values. The results are presented in Appendix 1.

[TABLE 1 HERE]

It should be noted that the underlying effect is not linear, the estimated effect sizes are quite small, and the model fit as measured by the adjusted $\mathrm{R}^{2}$ is modest. As the levels of conspiracy talk fluctuate, linear regression is an imperfect fit, and the results should not be treated as a formal test. Nonetheless, the calculated values suggest that across the period studied the incidence of conspiracy claims has declined steadily, while slap-downs have steadily increased. Thus the analysis based on the data taken from Hansard allows us to confidently dismiss any suggestion that conspiracy claims have become more prevalent over the course of the century 1916-2015. In fact, our model indicates that the likelihood that parliamentarians will claim that a conspiracy has taken place is declining by a small but significant proportion every decade. The onset of this decline occurs before 1965, when CT first appears in the data. This suggests that we would be best advised to regard the manner in which CT percolates into the parliamentary vocabulary more as a symptom of a broader skepticism of explanations and accusations appealing to notions of conspiracy, rather than as a driving factor behind this skepticism.

Our first finding is thus that conspiracy claims were not on the rise over the century extending from 1916 to 2015 and in fact have undergone a decline. A second significant finding can be discerned in the recognition that conspiracy claims are now exposed to an increased likelihood of a slap-down, many of which invoke CT. In fact, the data shows that 
the likelihood of a slap-down in response to a claim of $\mathrm{C}$ has for the most part been on the rise. $^{6}$

\section{Corroboration from a subsidiary result: The case of preemption}

This finding of a decline in conspiracy claims and an increase in slap-downs is complemented by observing trends in what we denoted above as preemption. Preemption was originally categorized as a form of hedging and thus assigned to a category that came to represent a catchment category for many statements whose meaning was ambiguous, at least with regard to its allocation to one of the other categories. However, we subsequently decided to salvage cases of preemption from this otherwise unusable "hedging" category upon realizing their significance for the issue of concern.

Preemption "hedges" a claim of an alleged conspiracy by prefacing it with a disclaimer designed to forestall any categorization of the claim or claim-maker to the generic categories of "conspiracy theory" and "conspiracy theorist." In fact, preemption can be thought to represent the absorption and the internalization of the conflicting voices illustrated at the beginning of this section in the exchange between the MPs Marlow and Jenkin: one voice (Marlow) makes a blasé accusation of conspiracy, the other voice (Jenkin) appeals to the generic category of CT to dismiss it. In preemption this conflict plays out not between MPs but rather within the locutions of a single speaker. To illustrate this, consider the following example from 2012, relating to attempts to deflect blame for the Hillsborough disaster of 1989 in which 96 football fans died: "I am not normally a conspiracy theorist, but in this case there clearly was a conspiracy" (Our italics. Hansard, 22 Oct 2012, col 777). On this occasion the conviction that there was a conspiracy trumped the inhibitions induced by the lack of seriousness associated with the generic category of CT. Of course, one can only speculate about the number of other cases in which such inhibitions overrode the willingness to voice a suspicion of conspiracy. 
We would expect cases of preemption to increase as an awareness grows of how the negative connotations of CT compromise claims of $\mathrm{C}$. We decided to explore this using the manageable data set of statements employing the term "conspiracy theorist": within a data set made up of 123 statements, we found 48 examples of preemption as achieved by a "but"statement ("I am not a conspiracy theorist, but ...") or a conditional ("If I were a conspiracy theorist, then I would almost say..."). Thus, over the last thirty years about $40 \%$ of statements employing the term "conspiracy theorist" employ it for the purpose of preemption. The development over time displays an increase in forms of preemption employing "conspiracy theorist”: 1986-1995: 4 times; 1996-2005: 18 times; 2006-2015: 26 times. We interpret this rise in cases of preemption to corroborate the finding discussed above involving a decline in conspiracy claims and a rise in slap-downs. All three trends reflect an increasing awareness that accusations of conspiracy, even if prima facie useful in the rough and tumble of

parliamentary politics, have become problematic in view of the often wayward explanation of political events and social phenomena they imply.

\section{Government "cock-ups" as an argument for deregulation and privatization}

Depending on the degree to which one identified with the world-view it implied, the marginalization of conspiracy claims represented either one of the achievements or one of the naivetés of post-war liberalism. The skepticism driving this marginalization was most cogently articulated in two lectures given by Karl Popper in late July and mid-August 1948. In these lectures, "the conspiracy theory of society" served as a foil to the correct understanding of social phenomena. This correct understanding was conscious of the fact that "nothing ever comes off exactly as intended" (Popper 2002, 166). For this reason, Popper believed that sociology should focus on the unintended consequences of social actions; those who instead equated social phenomena - and in particular unpleasant social phenomena such as "war, unemployment, poverty [and] shortages" - with intended consequences were 
susceptible to the allures of conspiracy theory. This argument, which had its precedents in the invisible-hand explanations of eighteenth-century thinkers who had seen in the unintended consequences of social action the source of social order, was integrated into the second edition of Popper's famous book The Open Society and its Enemies (1952). More generally, it was absorbed into the intellectual stance associated with Cold War liberalism (Müller 2008).

Because Popper drew his empirical points of reference from both the experience of National Socialism and Bolshevism - ideologies that scapegoated alleged racial and class enemies respectively - his argument chimed with the western liberal opposition to nondemocratic regimes. Yet the first serious engagement with Popper's specific arguments about the "conspiracy theory of society" would have to wait until the Cold War had passed. In 1995 the philosopher Charles Pigden published the essay: "Popper Revisited, or What is Wrong with Conspiracy Theories?" (Pigden 1995). The title of the first subsection: "Conspiracies, Cock-Ups and Sir Karl Popper," reflected a trope that had in fact only started to emerge in the 1970s and the 1980s. This trope pitted "conspiracies" against "cock-ups" as two alternative modes of explanation. Admittedly, cock-ups correspond to unintended consequences, and yet they also represent a more narrow subclass of this phenomenon: while unintended consequences are a concomitant to all social action and can, in certain circumstances, have positive and stabilizing effects, cock-ups more specifically imply mismanagement and incompetence.

The term "cock-up" has a ring of vulgarity that made its use in parliamentary debates a matter of debate in itself. In 1988 one MP let the chamber know that he had actually approached the deputy speaker in advance to ask "whether I could use the phrase 'cock-up' in this debate" (Hansard, 27 Apr 1988, col 414). The deputy speaker had expressed his reservations and voiced them again in the actual debate: "If those words were used too often, I believe that our debates would become somewhat inelegant" (Hansard, 27 Apr 1988, col 
414). The debate then assumes a Monty-Pythonesque quality (“ ... if anyone says 'Jehovah' once more ..."): although the deputy speaker has clearly declared his aversion to use of the term, the MPs cannot help themselves. Thus, one subsequent speaker MP reports that the "Minister said that they had made a cock-up. That is the sort of language that we are told should not be used, but it is what the Minister said" (Hansard, 27 Apr 1988, col 468). He then took the liberty of probing into the meaning of the term: "What does a cock-up mean? It means that they made a mess of it [...] The Minister told us that there was a cock-up, but he did not define exactly what that means."

For present purposes it is, however, not necessary to elaborate further on what the term itself means. More pertinent for present purposes is another question: what does the entry of the term into parliamentary vocabulary in the 1970s and 1980s mean? Furthermore, what does its frequent pairing with "conspiracy" signify? In attempting to answer such questions it is worth paying closer attention to the topic of the 1988 debate in which the term “cock-up" was - despite the misgivings of the deputy speaker - used a full eleven times. The cock-up in question had to do with prior assurances made in the House of Commons to not tamper with the regulations regarding Sunday opening hours for pubs. There had been a failure in coordination between the two chambers with the result that the House of Lords introduced an amendment allowing pubs to remain open an extra hour. As the conservative MP Douglas Hogg admitted: "There are two explanations. One is conspiracy, and the other is cock-up." He then assured the House that "It was [a] cock-up" (Hansard, 27 Apr 1988, col 444).

An extension of the opening times for pubs on Sunday of only one hour might seem a trivial matter but it is worth considering the terms in which the debate was conducted: opposition to the extended opening hours cited pressure upon employees, the adverse effects of increased alcohol consumption, particularly upon family life, and the traditional sanctity of 
Sunday. The other side appealed to "profitability" and a disbelief that "such restrictive laws could still operate in 1988" (Hansard, 27 Apr 1988, col 460). The willingness to abrogate such laws and to give free rein to market forces reflected a broader trend towards deregulation and privatization beginning in the 1980s. This policy was in part justified by the alleged susceptibility of government and bureaucracy (i.e. the public sector) to cock-ups.

As one might expect, the dominant pattern in Hansard reveals a preference for explanations in terms of cock-ups rather than conspiracies. Of the 86 occasions on which "conspiracy" was pitted against "cock-up" in the parliamentary record, on 55 occasions (or $64 \%$ ) "cock-up" was favored as the more plausible explanation. On other occasions some combination was suggested, as is evident from a comment given by the conservative and libertarian-leaning MP Eric Forth, who was particularly fond of the dichotomy: "We used to think that they [conspiracy and cock-up] were alternatives in the political lexicon, but this motion involves a combination of the two concepts. What started as a legislative cock-up has had to be translated by the Government into a conspiracy [...]" (Hansard, 10 Jun 2003, col 561). Only six occasions were found in which the conspiracy theory was deemed superior to the cock-up theory. The first occasion the opposition of conspiracy and cock-up appears was in November 1978 and for our decade units it then occurs the following number of times: 1976-1985: 4 times, 1986-1995: 23 times, 1996-2005: 32 times, 2006-2015: 27 times.

Of course, it is not easy to determine whether "[f]iascos and cock-ups in governance" actually had increased, as Lord Annan claimed in the House of Lords in 1997 (Hansard, 9 July 1997, col 679); after all, the oppositional nature of discourse in a parliamentary system encourages accusations of incompetence. The growing tendency to link governance with cock-ups from the 1980s onwards suggests, however, a broader frame for interpreting the semantic shift. This shift corresponds to a process of "antonym substitution" (Holmes 1996, 253-56); if the Cold War liberalism of a figure such as Karl Popper was evident in his 
aversion to conspiracy theories and in a corresponding preference for the invisible-hand explanations of the processes that generate society, neoliberalism retained the aversion to conspiracy theories but substituted the invisible-hand explanations of society with cock-up explanations as the antonym. (In this regard it is hard to avoid thinking of Thatcher's wellknown pronouncement that "there is no such thing as society." See Moore 2016 for the recognition that invisible-hand theories and cock-up theories have both functioned as the opposite to conspiracy theories). Indeed, in view of the link we posit between the uptake of "cock-up" as the antonym for conspiracy theory and the more general advance of neoliberal attitudes and policies, it seems significant that the statement that at least in part inspired Pigden to pit "conspiracies" against "cock-ups" came from Bernard Ingham, the press secretary to Prime Minister Margaret Thatcher: "Many journalists," Ingham declared in March 1985, "have fallen for the conspiracy theory of government. I do assure you that they would produce more accurate work if they adhered to the cock-up theory" (cited in Pigden 1995).

Our interpretation derives its plausibility not just from the conspicuous chronological congruence between the launch of the neoliberal program under the government of Margaret Thatcher and the uptake in the use of the trope opposing "conspiracies" and "cock-ups" throughout the 1980s. The link between neoliberalism and the use of "cock-up" is indicated, for example, by a sense of the semantic field in which "cock-up" was embedded, as conveyed by the conservative MP David Willetts in the course of a parliamentary debate that touched upon the burdens of regulation on business, the pitfalls of government provisions for parental leave and the privatization of the British postal service. Willetts summarized the debate by listing keywords: "regulation, costs, burdens, dogmatic, dog's dinner, damage, opportunistic, vacuum, cock-up, red tape, farce and incompetence" (Hansard, 19 Nov 1999, col 309). Juxtaposing this statement with a description by the geographer and social theorist David 
Harvey of a core belief of neoliberalism offers a curious overlap: "Privatization and deregulation combined with competition, it is claimed [by proponents of neoliberalism], eliminate bureaucratic red tape, increase efficiency and productivity, improve quality, and reduce costs, both directly to the consumer through cheaper commodities and services and indirectly through the reduction of the tax burden." (Our italics. Harvey 2005, 65). If regulation, red tape, costs and the tax burden could be reduced by an application of neoliberal policy, it is not a stretch to imagine that this would also entail a similar reduction in the number of cock-ups. After all, neoliberalism espouses a dim view of the capacity of public authorities to plan and intervene in social and (in particular) economic life, especially because such planning and intervention is unable to tap into the energies generated by self-interest but will instead need to draw upon motives that are both more idealistic and more vague (e.g. public service, public responsibility, the common good, etc.).

As is well known, the dominance of the neoliberal ideology survived the change of British government in 1997 (see Schulman 2015). The new labour government under Tony Blair retained the conviction that "private-sector firms could almost invariably be counted upon to outperform public-sector bodies. The private sector was [according to this view] almost always more efficient and effective than the public. Private-sector firms were under continuous pressure to adapt, innovate and cut costs. Public-sector organisations were under no such pressure. On the contrary, they were always in danger of becoming costly, bureaucratic monsters" (King and Crewe 2013, 202). Such costly, bureaucratic monsters were, for their part, in perpetual danger of committing cock-ups.

Thus in summary, the trope opposing "conspiracies" to "cock-ups" was significant for the way in which it managed to retain the liberal aversion to explanations in terms of conspiracies while at the same time adding a neoliberal spin by more narrowly characterizing the unintended consequences of the government's actions as “cock-ups", i.e. as specific 
instances of bungled action that collectively amounted to a record of mismanagement and incompetence and thereby undermined the case for government "intervention" in the first place. The significance of this development can be appreciated by asking more specifically about the particular "formula of rule" (to use the Foucauldian phrase (see Rose, 1996)) that encourages power-holders to admit cock-ups and, more fundamentally, engenders a situation in which cock-ups and conspiracies attain the congruence that then makes it necessary to argue that what looks like a conspiracy is actually a cock-up.

One answer is provided by the notion of a cover-up: the attempt to cover up a cock-up gives rise to the impression of a conspiracy. But the phenomenon of interest does not attempt to hide a cock-up but rather admits it as the lesser charge in comparison to the greater and more invidious charge of conspiracy. The key seems to lie in the way that the term "cock-up" appears so often in the context of government efforts to oversee deregulation and privatization. The admission of "cock-ups" pushes forward the neoliberal agenda by reinforcing the original message of endemic incompetence: even on those fronts from which government is retreating, it manages to bungle the process of retreat. Thus, speaking in 1992 about the impending lay-off of thirty thousand British miners, Lord Monkswell in the House of Lords conceded that a "great deal of blame does attach to the Government." He went on to argue, however that this development was "more a question of the cock-up theory of politics rather than of conspiracy. I do not believe that there was a conspiracy on the part of the Government to destroy the British mining industry [...] Yes, they changed the circumstances. They privatised the gas and electricity industries, and that has led to the present situation" (Hansard, 20 Oct 1992, col 539).

Of course, it has been noted on numerous occasions that in practice neoliberalism amounts less to a retreat of government and more to a reconfiguration of governance. In 1986 the Labour parliamentarian Frank Dobson astutely noted that his Tory colleagues in power 
were no longer acting in accordance with the tenets of traditional conservatism. Instead they were pursing policies that aimed to "get rid of institutions that have served for a long time, and substitute things that are almost bound to be cock-ups from the start" (Hansard, 10 December 1986, col 574). The institutions were not simply abolished but rather "substituted"; the tension between the professed disdain of bureaucracy and its reconfiguration and even expansion under neoliberal regimes has prompted Philip Mirowski to discern a "double truth" doctrine at the core of the ideology (Mirowski, 2015); what is openly advocated does not tally with the agenda that is covertly implemented. Mirowski dismisses an interpretation that equates neoliberalism with a conspiracy, yet it is not hard to see how this impression could arise. In a similar manner, cock-ups might genuinely represent an unintended consequence of implementing neoliberal policy, yet on a deeper level the evidence they provide of publicsector incompetence seems very much to conform with a core tenet of the new neoliberal ideology; as a result, one can be tempted to wonder whether such unintentional cock-ups were perhaps not so unintentional after all.

We do not suppose that every parliamentarian - or person for that matter - who invoked the opposition of "conspiracy" and "cock-up" espoused a neoliberal view of society and politics. Rather the subtle effects of ideologies are discernible precisely in the way in which such tropes percolate down into usage that does not amount to a conscious profession of political faith but nevertheless tilts the discourse in a certain direction. If our actions give rise to unintended consequences, we might also add to this the recognition that our words often have unintended implications and thereby entail unnoticed ideological affiliations.

\section{Conclusion}

The present study has focused on the way the prominence and status of conspiracy rhetoric on the field of political discourse has diminished over the second half of the twentieth century. Yet the research we have conducted employing Hansard as our data source 
has convinced us that we have only scratched the surface in terms of the potential insights further analysis could yield. As noted above, a more fine-grained thematic coding could identify how the "hot topics" for conspiracy rhetoric have varied over time. Presumably in areas where a greater consensus existed about a genuine threat (e.g. terrorism), claims of conspiracy, particularly when generated by the long process of downscaling an empire to a modern nation-state and (reluctantly) relinquishing former colonial possessions, would retain more plausibility. In other areas further removed from security concerns (e.g. education, the economy, culture, etc.) one would imagine the appeal to conspiracy to experience greater push-back (on the relationship between security and conspiracy, see Zwierlein and de Graaf 2013). It would be also interesting to investigate links between ideological profile and conspiracy mentality, i.e. the pre-established propensity to posit conspiracies as an explanation of events and developments (see Moscovici 1987 and, more recently, Imhoff and Bruder, 2014); although party affiliation is, of course, only a rough indicator of ideology preferences, it remains nevertheless an obvious place to start in exploring such matters. Further work could also move beyond the exclusive focus on "conspiracy" by considering other proximate vocabulary (plot, collusion, corruption, "the system is rigged," etc.). And finally, a more ambitious project could extend the analysis to parliamentary records in other parliamentary democracies and even consider the Congressional Record in the United States (whereby due consideration would need to be given to how differences in the institutional setting and political system impact upon the culture of discourse).

The assertion that conspiracy theories have been on the decline during this period has already been made by Butter and by Uscinski and Parent although neither of their works subject this decline to sustained analysis. Our analysis has corroborated their finding, at least for the historical record provided by Hansard. The proportion of statements mentioning conspiracy is roughly stable (notwithstanding some variations over the last century), but ever 
fewer of these statements are in fact claiming conspiracy and more of them are denouncing the appeal to the concept. This denunciation of conspiracy accusation as "conspiracy theories" was supplemented from the late 1970s / early 1980s onwards with the reference to "cock-ups" as the allegedly far more reliable explanans of what goes on in politics. We have argued on more qualitative grounds that this development represents a neoliberal inflection of the cold-war liberal understanding of society, particularly because the tendency was to associate cock-ups with government and the public sector.

As there might be a need to clarify our position on the trends we have observed and the way in which they relate to each other, we wish to speak cautiously of "correlations"; the claim, for example, that the label "conspiracy theory" has been the specific cause of the decline in conspiracy claims would amount to a conspiracy theory in itself (for an example of this kind of argument, see deHaven-Smith 2014). Use of the label reflects the low-level absorption of a model of liberal social science into general discourse. In the second half of the twentieth century political discourse became sociologically more sophisticated and less willing to indulge notions of nefarious plans with a preternatural level of successful coordination (see Thalmann 2014, for the American case). This development was reflected in the rising prominence of the term "conspiracy theory," which was one way - but not the only way - to convey skepticism of such notions.

Thus, one might say that British parliamentary discourse - and, one suspects, political discourse in liberal democracies in general - was characterized by a growing prejudice against conspiracy claims now that they were liable to be denoted as "conspiracy theories." Prejudices can undoubtedly be problematic and it is not difficult to find examples of how the term "conspiracy theory" has been deployed to stifle criticism and skepticism that subsequent events have demonstrated to be warranted. When the Labour MP Siôn Simon defended the U.S. and British invasion of Iraq in 2003 by claiming that "[o]nly in the minds of mad 
conspiracy theorists does this country launch illegal wars" (Hansard, 22 May 2006, col 1218), then it is clear that he deployed the term "conspiracy theorist" (in conjunction with the attribute of madness) to delegitimize what many, particularly with the benefit of hindsight, would consider healthy skepticism of government foreign policy.

On the other hand, reading through many of the conspiracy claims also makes it clear that some means of flagging down the excesses of conspiracy rhetoric is warranted. "Conspiracy theory" as a term was coined to address the way that explanations that appeal to conspiracy mistake and obscure the real nature of social developments. Thus, in 1922 Lieut.Colonel Morre-Brabazon asserted that "All education in this country is really a conspiracy to delay the sexual growth of the boy" (Hansard, 5 July 1922, col 510). Indeed, such a statement seems so outlandish that it is possible to ask whether this is a metaphorical use of “conspiracy." More pointedly, conspiracy claims have taken on the negative reputation of conspiracy theories not just because of their misrepresentation of social reality but because of their tendency to become "self-sealing" (Sunstein and Vermeule, 2009): they dismiss evidence that refutes them with the claim that this "evidence" has been planted by the conspirators. In other words, for those opposed to conspiracy theories, it is not just that the conspiracy theorists are wrong, but that it is so hard to get them to admit being wrong.

In conclusion, it hardly seems plausible that Karl Popper, in promoting the dissemination of the term "conspiracy theory," was intending to provide cover for real conspiracies. Rather he invoked the term to address a genuine problem. The fact that the term, in addressing this problem, has revealed itself as problematic in its own ways can undoubtedly be chalked up as one of those unintended consequences so important for Popper and others in understanding how society actually works.

Everyone knows the story about the boy who cried wolf. By contrast, few people know the story about the parliament who cried conspiracy. There is a simple reason for that: 
this story is buried in shifting patterns of semantics that have only become discernible since the recent digitization of Hansard opened up the discourse within the British parliament to investigation by computational methods. This investigation shows that, whereas in the past British parliamentarians were more than willing - and perhaps too willing - to make accusations of conspiracy, over the course of the last fifty years they have shown an increasing reluctance to 'play the conspiracy card' in their debates in the House of Commons and the House of Lords. The reason for this reluctance is not so much a fear of being ignored like the boy who cried wolf but rather a fear of being mocked for peddling 'conspiracy theories.' Such mockery might be defensible in specific cases and even in a majority of such cases. We need, however, to be mindful of the fact that it is always in danger of overlooking the fact that conspiracies - like wolves - really do exist.

\footnotetext{
${ }^{1}$ As a term of British vernacular to denote a blunder or gaffe, "cock-up" retains a vulgar ring; one presumably would not use it in conversation with the Queen, though that has not stopped is usage on close to four hundred occasions in her parliament. After presenting an earlier version of this work, our project administrator told us that her use of the term "cock-up" had once caused her mother to give her a "slap-down". Upon hearing this, we decided to run with our title.

${ }^{2}$ Butter (2014, 32-54) gives some reasons why American political culture has admittedly provided especially fertile ground for this phenomenon.

${ }^{3}$ Because we have taken our source material from both the House of Commons and the House of Lords, the latter of which is a non-elected body with lifetime membership, and because the House of Commons retains a very large portion of its membership after general elections, we felt justified in treating Hansard as a more or less continuous body of discourse that we can subdivide into units on the (admittedly arbitrary) basis of decades.
} 


\footnotetext{
${ }^{4}$ The same effect can be observed using Google's ngram, admittedly with a somewhat later date (approx. 1988) for when "conspiracy theory" begins to exceed "conspiracy of silence" in terms of usage.

${ }^{5}$ It was decided to leave out the category of rejection, in part because rejections, in disputing the existence of a conspiracy but implicitly admitting its possibility, partake of the same "worldview" as those putting forward the conspiracy claim; in other words, the pertinent contrast is between the categories of conspiracy claims and slap-downs.

${ }^{6}$ Replication materials available upon request.

${ }^{7}$ It is, however, possible to find equivalent examples predating the entry of CT into the parliamentary vocabulary, as for example when in 1931 a statement was introduced by the following expression: "Without saying that there has been a conscious and deliberate conspiracy ...”(Hansard, 23 Sept 1931, col 1713).
} 


\section{References}

Barkun, M. 2013. Culture of Conspiracy: Apocalyptic visions in Contemporary America. Berkeley, CA: University of California Press.

Boltanski, L. 2014. Mysteries and Conspiracies: Detective Stories, Spy Novels and the Making of Modern Societies. Cambridge: Polity Press.

Bright, J. 2012. The Dynamics of Parliamentary Discourse in the UK: 1936-2011. Paper presented at Internet, Politics and Policy: Big Data, Big Challenges?, 20-21 September 2012, Oxford Internet Institute.

Butter, M. 2014. Plots, Designs, and Schemes: American Conspiracy Theories from the Puritans to the Present. Berlin. Walter de Gruyter.

Coady, D. 2012. What To Believe Now: Applying Epistemology to Contemporary Issues. Chichester: Wiley-Blackwell.

Dentith, M. 2014. The Philosophy of Conspiracy Theories. Basingstoke: Palgrave MacMillan. deHaven-Smith, L. 2014. Conspiracy Theory in America. Austin, TX: University of Texas Press.

Hansard HC Deb vol 142 col 1328 (2 Jun 1921) [Electronic version]

Hansard HC Deb vol 156 col 410 (5 July 1922) [Electronic version] Hansard HC Deb vol 236 col 1550 (13 Mar 1930) [Electronic version] Hansard HC Deb vol 256 col 1713 (23 Sept 1931) [Electronic version] Hansard HC Deb vol 449 col 193 (7 Apr 1948) [Electronic version] Hansard HL Deb vol 155 cols 267, 315 (21 Apr 1948) [Electronic version] Hansard HC Deb vol 450 col 992 (3 May 1948) [Electronic version] Hansard HL Deb vol 270 col 883 (23 Nov 1965) [Electronic version] Hansard HL Deb vol 379 col 144-216 (20 Jan 1977) [Electronic version] 
Hansard HC Deb vol 983 col 1306 (29 Apr 1980) [Electronic version]

Hansard HC Deb vol 107 col 574 (10 Dec 1986) [Electronic version]

Hansard HC Deb vol 132 cols 414, 444, 460, 468, (27 Apr 1988) [Electronic version]

Hansard HL Deb vol 539 col 729 (20 Oct 1992) [Electronic version]

Hansard HL Deb vol 581 col 679 (9 July 1997) [Electronic version]

Hansard HC Deb vol 317 col 840 (2 Sept 1998) [Electronic version]

Hansard HC Deb vol 339 col 309 (19 Nov 1999) [Electronic version]

Hansard HC Deb vol 406 col 561 (10 Jun 2003) [Electronic version]

Hansard HC Deb vol 415 col 13 (26 Nov 2003) [Electronic version]

Hansard HC Deb vol 424 col 927 (9 Sept 2004) [Electronic version]

Hansard HC Deb vol 446 col 1218 (22 May 2006) [Electronic version]

Hansard HC Deb vol 551 col 777 (22 Oct 2012) [Electronic version]

Harvey, D. 2005. A Brief History of Neoliberalism. Oxford: Oxford University Press.

Holmes, S. 1996. The Anatomy of Antiliberalism. Cambridge, MA: Harvard University Press.

Husting, G., \& Orr, M. 2007. Dangerous Machinery: “Conspiracy Theorist” as a

Transpersonal Strategy of Exclusion. Symbolic interaction, 30(2):127-150. doi:10.1525/si.2007.30.2.127

Imhoff, R. \& Bruder, M. 2014. Speaking (Un-)Truth to Power: Conspiracy Mentality as a Generalised Political Attitude. European Journal of Personality, (28): 25-43. doi:10.1002/per.1930

Jack, M. (ed.) 2011. Erskine May: Parliamentary Practice (24 ed.). London: LexisNexis.

King, A. \& Crewe, I. 2013. The Blunders of Our Governments. London: One World Publications. 
Mirowski, P. 2015. Postface: Defining Neoliberalism. In The Road from Mont Pèrelin. The Making of the Neoliberal Thought Collective. Cambridge, MA: Harvard University Press.

Moore, A. 2016. Hayek, Conspiracy, and Democracy. Critical Review 28(1):44-62. doi:10.1080/08913811.2016.1167405

Moscovici, S. 1987. The Conspiracy Mentality. In Changing Conceptions of Conspiracy. Edited by C. F. Graumann and S. Moscovici. New York: Springer-Verlag.

Mülller, J.-W. 2008. Fear and Freedom. On “Cold War Liberalism”. European Journal of Political Theory, 7(1):45-64. doi:10.1177/1474885107083403

Pigden, C. 1995. Popper Revisited, or What is Wrong With Conspiracy Theories. Philosophy of the Social Sciences. 25(3):3-34. doi:10.1177/004839319502500101

Popper, K. 2002. Conjectures and Refutations. The Growth of Scientific Knowledge. London: Routledge \& Kegan Paul.

Rose. N. 1996. Governing “advanced” liberal democracies. In Foucault and political reason. Liberalism, neo-liberalism and rationalities of government. Edited by A. Barry, T. Osborne and N. Rose. London: UCL Press.

Russell, M. 2013. The Contemporary House of Lords. Westminster Bicameralism Revisited. Oxford: Oxford University Press.

Schulman, J. 2015. Neoliberal Labour Governments and the Union Response. The Politics of the End of Labourism. Basingstoke: Palgrave-MacMillan.

Sunstein, C. \& Vermeule, A. 2009. Conspiracy Theories. Causes and Cures. The Journal of Political Philosophy, 17(2):202-227. doi:10.1111/j.1467-9760.2008.00325.x

Thalmann, K. (2014) “John Birch Blues": The Problematization of Conspiracy Theory in the Early Cold-War Era. Current Objectives of Postgraduate American Studies 15(1):117. doi:10.1353/ams.2016.0019 
Uscinski, J. E., \& Parent, J. M. (2014). American Conspiracy Theories. Oxford. Oxford University Press.

Zwierlein, C., \& de Graaf, B. (eds.) 2013. Security and Conspiracy in History, 16th to 21st Century. Special issue of Historical Social Research 38(1). 